\title{
La imagen del periodista y el sensacionalismo en la ficción televisiva. El caso de las comedias animadas de prime time
}

\author{
Beatriz María Gómez Morales \\ Universitat Autònoma de Barcelona \\ beatrizmaria.gomez@e-campus.uab.cat
}

Recibido 16 de mayo de 2013

Aceptado: 3 de octubre de 2013

\section{Resumen}

La frecuente introducción de segmentos informativos ficticios en las comedias animadas de prime time ofrece una seria reflexión crítica sobre el actual estado del periodismo televisivo. Como textos paródicos, las noticias del Canal 6 (Los Simpson), del Canal 84 (El rey de la colina), del Canal 4 (South Park), del Canal 5 (Padre de familia) y del Canal 3 (American Dad) reproducen con exactitud los elementos formales del informativo, mientras que su contenido sufre una notable transformación y es exagerado en aras de señalar una tendencia mediática: la transferencia de los códigos de la prensa sensacionalista al universo televisivo.

Palabras clave: Comedias animadas de prime time, periodismo, sensacionalismo

The image of the journalist and the tabloidization in television fiction. The case of prime time animated comedies

\begin{abstract}
The frequent introduction of fictitious news segments in prime time animated comedies offers a serious critical reflection on the current state of television journalism. As parodic texts, news of Channel 6 (The Simpsons), Channel 84 (The King of the Hill), Channel 4 (South Park), Channel 5 (Family Guy) and Channel 3 (American Dad) accurately reproduce the formal elements of television news, while its content undergoes a remarkable transformation and it is exaggerated in order to underline a media trend: the transfer of tabloid press codes to television universe.
\end{abstract}

Keywords: prime time animation comedy, journalism, tabloidization

\section{Referencia normalizada}

GÓMEZ MORALES, Beatriz María (2014): "La imagen del periodista y el sensacionalismo en la ficción televisiva. El caso de las comedias animadas de prime time". Estudios sobre el Mensaje Periodístico. Vol. 20, Núm. 2 (julio-diciembre), págs.: 719-734. Madrid, Servicio de Publicaciones de la Universidad Complutense.

Sumario: 1. Introducción. 2. Fuentes y metodología. 3. El sensacionalismo en las comedias animadas de prime time; 3.1. La figura del presentador y el culto a la personalidad; 3.2. Selección y jerarquización de las noticias; 3.3. Exposición de la información; 3.4. Escenificación de la noticia; 3.4.1. Reporteros del sensacionalismo; 3.5. Intereses económicos y políticos. 4. Conclusiones. 5. Referencias bibliográficas.

\section{Introducción}

Aunque el sensacionalismo es casi tan antiguo como el mismo periodismo moderno, en las últimas dos décadas se ha evidenciado una marcada tendencia hacia este modelo de presentación de los hechos y numerosos estudios académicos así lo han demostrado (Ortoleva, 1995; Brants, 1998; Winston, 2002; Prado, 2003; Gencel, 2004; Díaz Nosty, 2006; García Avilés, 2007; Labio Bernal, 2008, entre otros). Graeme Turner (1999: 59) asegura que, en los últimos años, en el Reino Unido, Estados Unidos 
de América y Australia ha habido un cambio sustancial en los procesos de priorización de los sucesos noticiosos y el tratamiento de la información: la política ha cedido su lugar al crimen, los temas sociales a la vida privada de las celebridades y ha habido una inversión abrumadora sobre el poder de lo visual. En otras palabras, sensacionalismo, definido por Spark (Spark y Tulloch, 2000: 10) como el predominio de los deportes, el escándalo, el entretenimiento popular y la vida privada de las personas, tanto celebridades como gente corriente, ante los procesos políticos, el desarrollo económico y el cambio social.

Aun con más contundencia que Turner, Bob Franklin (1997) afirma que el escándalo y el sensacionalismo se han convertido en los ingredientes centrales de la dieta mediática y los criterios de valoración periodística se han invertido:

"El entretenimiento ha sustituido a la información, el interés humano han reemplazado el interés público, el juicio mesurado ha sucumbido ante el sensacionalismo, lo trivial ha triunfado sobre lo relevante, la vida privada de las celebridades, el mundo del deporte o la familia real son considerados informativamente más valiosos que los reportajes sobre temas significativos y acontecimiento con consecuencias internacionales" (Franklin, 1997: 4).

Según Franklin, la inversión es resultado de un cambio en la estructura, la regulación y las prácticas profesionales del periodismo que ha penetrado en todos los medios. Andrew Calabrese (2000: 45) defiende esta afirmación y señala que incluso, las tres grandes cadenas norteamericanas, ABC, NBC y CBS, se han apuntado a la tendencia sensacionalista.

De forma general, el sensacionalismo es criticado y condenado por sacrificar la información ante el entretenimiento. No obstante, el término no siempre es empleado como calificativo negativo. Una importante corriente de los estudios académicos, impulsada por Fiske (1992) y Hartley (1996), defiende su carácter democratizador. Fiske, y posteriormente Van Zoonen (1998), destacan que, a diferencia del periodismo tradicional, el tabloide puede ser transgresor y tiene el potencial para criticar las normas y valores de la postura dominante y oficial. Hartley, como Lumby (1999), se opone a una oposición entre información y entretenimiento, hard news y soft news y la esfera pública y la privada que busca perpetuar una hegemonía cultural. Bird (2000) alega que el sensacionalismo permite la circulación de contenidos alternativos y Glynn (2000) señala su capacidad para multiplicar y amplificar puntos de vista heterogéneos y dar voz a los discursos minoritarios; mientras que Langer (2000) defiende que las "otras noticias", es decir, aquellas sobre desastres naturales, accidentes de tráfico, tragedias personales o actos heroicos, deben ser tratadas con el mismo interés y respeto que las noticias consideradas importantes según los estudios críticos.

No obstante, el periodismo sensacionalista ha demostrado ir más allá de la priorización de unas noticias sobre otras y de exaltar el entretenimiento por encima de la información. Según la definición de Martínez de Sousa (1981: 474), el sensacionalismo de fondo o de contenido se alimenta de exageraciones tanto en los títulos, falseando el contenido de la noticia que sigue, como de los textos. En la misma línea, López de Zuazo (1985: 182) define el sensacionalismo como "periodismo poco objetivo que exagera con titulares, fotografías o textos las noticias de escándalos, sucesos san- 
grientos o morbosos y noticias de interés humano". Mientras que Sunkel (2001: 118) asegura que "el sensacionalismo se basa en una descripción exagerada y por tanto distorsionada de ciertos sucesos con el fin de generar un impacto emocional".

De esta manera, la discusión se desplaza del terreno de los criterios y valores noticiosos de unas noticias u otras, al del contenido de dichas noticias. Si entendemos el sensacionalismo únicamente como una transformación en las temáticas, corremos el riesgo de subestimar su poder. Jonathan Alter afirma que si todo es entretenimiento, todo se reduce en significado y así corremos el riesgo de perdernos en una jungla de ruido (Alter, 1999). El sensacionalismo no sólo disminuye el espacio y el tiempo para la presentación de información relevante en el discurso democrático. También se caracteriza por ofrecer una información que ni siquiera es completamente verídica; un información que en muchos casos falsea la realidad.

\section{Fuentes y metodología}

A pesar de las numerosas producciones de ficción televisiva dedicadas al ejercicio del periodismo (The Mary Tyler Moore show [CBS, 1970-77], Lou Grant [CBS, 1977-82], Murphy Brown [CBS, 1988-98], Dirty [FX, 2007-08], The newsroom (HBO, 2012-), etc.) y aquellas en las que aparecen personajes dedicados a esta profesión, aunque la trama central este centrada en otras cuestiones, la representación de los periodistas en la televisión ha sido escasamente analizada. No obstante, es preciso destacar el trabajo de Douglass K. Daniel (1996), dedicado a la serie Lou Grant, en el que en el primer capítulo explora el drama periodístico como género televisivo y hace un recorrido histórico por todas sus producciones entre 1947 y 1977. Por el contrario, en el ámbito cinematográfico, la figura del periodista y sus prácticas laborales han sido ampliamente abordadas. Los trabajos de Alex Barris (1976) y Richard Ness (1997) ofrecen un catálogo completo de las producciones cinematográficas dedicadas al mundo del periodismo, mientras que los estudios de Howard Good (1989, 1998 y 2000), Mathew Ehrlich (1997 y 2004), Ofa Bezunartea et al. (2007) y Brian McNair (2010), entre muchos otros, analizan en profundidad las representaciones de los profesionales de la información en las producciones de Hollywood.

Bezunartea et al. (2007) y Brian McNair (2010) coinciden al señalar que la imagen de los periodistas en el cine es predominantemente positiva. Bezunartea et al. afirman que los periodistas de cine se decantan por comportamientos bastante o muy éticos (376) y McNair asegura que en el 82\% de las películas estrenadas entre 1997 y 2008, dedicadas al periodismo, los profesionales son retratados como personas buenas, valientes, comprometidas con su trabajo y defensoras de sus ideales (48). No obstante, añade McNair, existe la creencia general de que el cine tiende a retratar a los periodistas de forma negativa como consecuencia de unas pocas producciones que han marcado la historia del medio: Citizen Kane (1941), Ace in the Hole (1951), Sweet smell of success (1957), Natural born killers (1994) o To die for (1995).

La ausencia de investigaciones de este mismo tipo en el campo de la televisión no permite confrontar imaginario colectivo y representación televisiva. Joe Saltzman (2003) afirma que las dos imágenes más positivas del periodismo en la cultura popular corresponden a dos presentadoras de informativos: Mary Richards, personaje prin- 
cipal de The Mary Tyler Moore Show, y Murphy Brown, protagonista de Murphy Brown. No obstante, el visionado de otras series dedicadas al periodismo, como The Naked Truth (ABC, 1995-96; NBC, 1996-98) y NewsRadio (NBC, 1995-99), y de diversas producciones en las que son presentadas periodistas, como Married... with children (Fox, 1987-97), Law and order (NBC, 1990-2000), CSI (CBS, 2000-) o Bones (Fox, 2005-), demuestra que la representación de esta profesión en la televisión también puede ser negativa. En estos casos, las producciones televisivas, como las cinematográficas, no están impulsadas por el simple deseo de desacreditar a los periodistas, sino de funcionar como "vigilantes de los vigilantes". Desde un estadio superior, vigilan el periodismo y las instituciones e individuos que el periodismo está encargado de vigilar (McNair, 2010: 138).

Este trabajo pretende avanzar en el estudio de la imagen del periodista en la televisión y analiza la representación de dicha profesión en un subgénero televisivo concreto, la comedia animada de prime time. Las producciones más populares y longevas de este subgénero, es decir, Los Simpson (The Simpsons, Fox, 1989-), El rey de la colina (King of the Hills, Fox, 1997-2009), South Park (Comedy Central, 1997-), Padre de familia (Family Guy, Fox, 1999-) y American Dad! (Fox, 2005-) introducen segmentos de informativos ficticios en la mayoría de sus episodios y cuentan con personajes principales o secundarios que se dedican al periodismo. En estas cinco comedias se manifiesta el cambio sustancial en el tratamiento de la información señalado por Turner (1999) y sus informativos exhiben todas las características atribuidas al sensacionalismo, tanto las relativas a la selección de las temáticas de las noticias como el uso de recursos tales como la exageración.

De acuerdo con esta perspectiva, la representación del periodismo y el sensacionalismo es abordada a través del análisis del discurso (Dijk, 1980) de los informativos ficticios de las cinco comedias animadas de prime time. El análisis abarca todas las temporadas de las cinco series, lo que representa un total de 1.321 episodios, y contempla cinco variables. Dichas variables están basadas en las fases de la creación discursiva establecidas por la retórica, es decir, inventio, dispositio, elocutio, memoria y actio (Cicerón, 2002; Quintiliano, 2004); en las etapas básicas del proceso de la producción periodística (Dijk, 1990) y en las categorías desarrolladas por Ehrlich (1997 y 2004) para el análisis de la representación del periodista en el cine. Las cinco variables son:

1. La figura del presentador/a.

2. La selección y jerarquización de los acontecimientos.

3. La exposición de la información.

4. La escenificación de la noticia.

5. El contexto económico y político de la noticia.

\section{El sensacionalismo en las comedias animadas de prime time}

Cada una de las cinco comedias animadas que conforman la muestra, cuenta con un equipo de noticias y un informativo muy popular entre sus personajes. El noticiario de Canal 6 (Los Simpson) está liderado por Kent Brockman y esporádicamente cuenta con la colaboración de Arnie Pye, reportero del tráfico. La unidad periodística del infor- 
mativo del canal 84 (El rey de la colina) está conformado por Miguel Hernández, Nancy Hicks Gribble, Don Ringle e Irv Bennett, aunque el único personaje en el que se desarrolla el rol profesional es en Nancy, chica del tiempo y posteriormente copresentadora del informativo. Las noticias del Canal 4 (South Park) son presentadas por Tom Pusslicker y el informativo cuenta con un variopinto grupo de reporteros. Durante las primeras ocho temporadas de Padre de familia, las noticias de acción del Canal 5 eran presentadas por Diane Simmons y Tom Tucker. No obstante, tras su muerte, Simmons es reemplazada por Joyce Kinney. El meteorólogo Ollie Wiliams y la reportera Tricia Takanawa también trabajan para las noticias del Canal 5. Por último, Terry Bates y Greg Corbin son los presentadores y únicos miembros del equipo periodístico del informativo del Canal 3 (American Dad).

\subsection{La figura del presentador y el culto a la personalidad}

El culto a la personalidad es un elemento esencial del sensacionalismo en los informativos (Calabrese, 2000: 44). La incorporación de la lógica de los programas de entretenimiento en los informativos ha cambiado drásticamente el rol de los presentadores de noticias. Incluso, los más conservadores, han sucumbido ante el cambio de paradigma y han pasado de ser dinamizadores de la opinión pública para convertirse en entretenedores. Según Jonathan Alter (1999: 15), año tras año, los presentadores de noticias dan paso a los directores de circo de la conversación.

Andrew Calabrese (2000) señala que, en América, las encuestas indican una clara preferencia de la audiencia por los informativos con presentadores atractivos y reporteros heroicos; lo que ha suscitado un cambio en el criterio de selección de los profesionales: el atractivo físico se impone a la trayectoria profesional. Y Norman Corwin (1986: 33) afirma que el equipo de presentadores de un informativo local se caracteriza por un chico del tiempo atractivo con chispa o encanto, presentadoras con sonrisas bonitas y peinados elegantes y presentadores deportivos masculinos y con carisma.

En las comedias animadas, el mejor ejemplo de "físico sin sustancia" es Nancy Hicks Gribble. Nancy es una mujer vanidosa y presumida que sabe a ciencia cierta las razones por las cuales trabaja en el informativo: su atractivo físico y, en concreto, su melena rubia. De la misma manera que Nancy, el resto de presentadores en la series animada suelen preocuparse por su aspecto y ser considerados atractivos. Por ejemplo, Greg Corbin y Terry Bates, de American Dad, son metrosexuales y Tom Tucker, de Padre de familia, es objeto de deseo de la mayoría de mujeres de Quahog. Suele caminar muy lentamente, como si fuera a cámara lenta, para parecer más atractivo y se presenta a sí mismo como "hombre apuesto con bigote recopila las noticias con su agradable voz de barítono". Incluso Kent Brockman, quien representa al periodista ve-

1 En el episodio Atrapar al ladrón (PF, T4.E1). Para facilitar la localización de los episodios mencionados, cada cita incluye, entre paréntesis, las iniciales del nombre de la serie (LS para Los Simpson, RC para El rey de la colina, SP para South Park, PF para Padre de familia y AD para American Dad), el número de la temporada y de episodio (T para temporada y E para episodio). 
terano y consagrado, se preocupa demasiado por su aspecto físico. Por ejemplo, se inyecta toxina botulínica (botox) o se ata las arrugas con pinzas de la ropa en la nuca, para parecer más joven.

\subsection{Selección y jerarquización de las noticias}

La introducción de segmentos del informativo suele responder a dos modalidades. En primer lugar, puede responder al hecho de que uno de los personajes sea el protagonista de la noticia o que los acontecimientos explicados en el informativo den un giro a la narración. En estos casos, las historias presentadas se refieren a hechos que afectan de manera concreta a las familias protagonistas de las series, más allá de ser hechos de gran relevancia informativa o no. Por ejemplo, en Por quién doblan las campanas de los trineos (AD, T6.E8), Terry entrevista a varias personas por la calle y acaba el reportaje afirmando que, a pesar de ser la víspera de navidad, muchas personas afirman no sentir el espíritu navideño, como si alguien hubiese matado a Santa Claus. Y en efecto, Steve Smith, uno de los protagonistas de la serie, ha matado involuntariamente al famoso personaje navideño, hecho que justifica la presentación de la noticia.

En segundo lugar, las secuencias del informativo tienen como objetivo la generación de risa, de manera que los acontecimientos se pueden referir a cualquier tema. En estos casos, es notorio y habitual que los informativos de las comedias animadas de prime time presten excesiva atención a acontecimientos banales, que no revisten la más mínima importancia. Por ejemplo, Kent Brockman informa sobre una ola de golpes con toallas enrolladas en Lisa, la Simpson (LS, T9.E17) y sobre un campo nudista para animales en El día del apaleamiento (LS, T4.E20); mientras que en Más vale un Smith en mano (AD, T1.E9), Terry explica la noticia de un mono que recibió unos azotes y fue castigado en el zoológico de la ciudad.

No obstante, el ejemplo paradigmático de la representación de sucesos triviales en las comedias animadas es presentado en el episodio La nueva imagen de Britney (SP, T12.E2). En dicho episodio, se introduce como "noticia urgente de última hora" un boletín titulado ¡En el ojo de Britney!, que informa sobre las últimas novedades en la vida de Britney Spears. El presentador afirma que Spears ha sido vista acampando en las montañas de Colorado y conecta con un reportero que se encuentra en la zona. El reportero, muy excitado, anuncia que tiene una noticia increíble y declara que la diva del pop ha orinado sobre una mariquita. Gracias a equipos de alta tecnología, se amplía una imagen de Spears mientras orina para captar el momento preciso en que el líquido cae encima del pequeño animal y lo aniquila. Más adelante, en el mismo episodio, aparece una multitud de periodistas rodeando el motel en que se especula se aloja la artista. La amplia cobertura del suceso no solo llama la atención porque responde a uno de las principales temáticas del periodismo sensacionalista, la vida privada de las celebridades, sino porque su presentación interrumpe un acontecimiento de gran relevancia, el debate político entre Hilary Clinton y Barack Obama, aunque el presentador del boletín de Spears considera que es el "estúpido debate de los demócratas". Es preciso señalar, que la secuencia no es presentada por el canal local de South Park, sino como una parodia de Fox News, cadena ampliamente criticada por su postura abier- 
tamente republicana y propiedad de Ruperd Murdoch, una de las figuras empresariales centrales del sensacionalismo mediático (Glynn, 2000: 27).

Pero la prevalencia de noticias carentes de relevancia informativa, la cobertura de hechos banales y la degradación a un segundo plano de los sucesos de alta trascendencia no es solo una característica única de Fox News en South Park. Kent Brockman y Tom Tucker también son incapaces de priorizar correctamente las noticias y presentarlas en función de su grado de relevancia. Por ejemplo, en Lisa contra Stacy Malibú (LS, T5.E14), Brockman, después de agotar el espacio del informativo hablando de la nueva muñeca que ha salido al mercado y haberse despido de la audiencia dice: "Oh, y el Presidente ha sido arrestado por asesinato. Más acerca de esta noticia mañana". Y en El rey ha muerto (PF, T2.E7), Tucker abre el informativo con la noticia del rescate de un pez que quedó atrapado en un laguna congelada y relega a un segundo plano la muerte del director del teatro de la ciudad.

\subsection{Exposición de la información}

En la labor de convertir simples acontecimientos cotidianos en importantes noticias, los periodistas de las comedias animadas se ven obligados a caer en la exageración y el sobredimensionamiento. Durante el proceso, las noticias se transforman en espectáculo, de manera que dejan de interpelar a los espectadores como ciudadanos y simplemente los conciben como consumidores y puntos en los niveles de audiencia.

La exageración es una estrategia muy eficaz para atraer a la audiencia pero puede ocasionar un amplio abanico de efectos colaterales. No obstante, esto hecho no parece preocupar a los periodistas de las comedias animadas, quienes la han convertido en su principal aliada. Sin pensar en el pánico que la noticia puede desatar en la audiencia, Mitch, un reportero del Canal 4 de South Park, informa que la catástrofe de Beaverton ha causado la muerte de cien millones de personas, aunque afirma que la localidad solo tiene 8.000 habitantes y el desastre natural no parece haber afectado otras poblaciones. Mitch, interesado en mantener a la audiencia en alerta, añade que se encuentra a las afueras de Beaverton porque es imposible acceder, dado que ya han iniciado los saqueos masivos y seguramente los sobrevivientes han sucumbido al canibalismo. Tom Pusslicker, presentador del informativo, pregunta alarmado a Mitch si ha podido ver a personas fornicando, violando y comiéndose unos a otros, pero Mitch, con toda naturalidad, responde que en realidad no han visto nada y que por eso solo lo "informa", no lo afirma (Dos días antes de pasado mañana [SP, T9.E8]).

Kent Brockman también disfruta sobredimensionando todas las noticias, por ello en El saxo de Lisa (LS, T9.E3) afirma que la temperatura máxima del día ha batido el récord hasta la fecha, record que se estableció hace 4 billones de años cuando la tierra era solo una bola de lava fundida. Y en Kampamento Krusty (LS, T4.E1) asegura que la revolución que han liderado los niños en un campamento de verano es un millón de veces peor que lo ocurrido en Vietnam, Afganistán e Irak juntos. No obstante, la mayor muestra de su marcada tendencia a la exageración la encontramos en Homer, hombre malo (LS, T6.E9). Gracias a una cámara de detección de calor del Canal 6, Brockman consigue ver el interior de la casa de los Simpson y, aunque confiesa no conocer bien esa tecnología, asegura que quien está dentro del horno es Homer Simp- 
son, asándose en su propio jugo. Para la audiencia, la imagen es muy clara, lo que hay dentro del horno es un pollo, pero el afán de Brockman por mantener la noticia viva y atrapar al espectador es tal que está dispuesto a fabular contra el sentido común.

Después de enseñar la casa de los Simpsons, Brockman ofrece los resultados de una encuesta e informa que el $95 \%$ de los participantes piensa que Homer Simpson, acusado de acoso sexual, es culpable. Brockman destaca que solo se trata de una encuesta televisiva sin vigencia legal, a menos que se apruebe la propuesta 304 , acontecimiento por el que todos, incluido él mismo, están rezando. De esta manera, Brockman no solo invade la privacidad de los Simpsons y especula sobre sus actos, sino que abiertamente ponen en cuestión la inocencia de Homer y desea que sea juzgado culpable sin celebrarse un juicio justo.

La defensa de la culpabilidad o inocencia de los sujetos involucrados en la noticia y la opinión personal de los presentadores es una de las estrategias sensacionalistas que privilegian la personalización y la dramatización de la cobertura periodística. En las comedias animadas, los presentadores también se caracterizan por editorializar los sucesos que presentan de manera que parezcan más impactantes. Brockman es un genio de la especulación y el dramatismo, así lo demuestran el ejemplo anterior y decenas de segmentos. En Marge se da a la fuga (LS, T5.E6) informa sobre la persecución policiaca en la que se han visto involucradas Marge Simpson y su amiga Ruth Powers y, desconociendo las causas de ésta, se arriesga a afirmar que las dos mujeres son culpables y se las debe tratar de manera dura y brutal. De lo contrario, su conducta podría incitar a otras mujeres, llevándonos a una anarquía de proporciones bíblicas. Tucker, aunque en menor medida, tampoco reprime sus opiniones delante de las cámaras y en Arma letal (PF, T3.E7), cansado de que cada año miles de neoyorquinos invadan la ciudad para ver la caída de las hojas en otoño, sentencia: "Bueno, creo que hablo en nombre de todos cuando digo que todos los neoyorquinos se pueden meter un palo por donde ya saben". De igual manera, el presentador del informativo del Canal 4 afirma que el padre de Kyle es un "cabrón" por ser abogado defensor y acusador en un juicio que enfrenta a todo el pueblo (El panda del acoso sexual [SP, T3.E6]) y Tom Pusslicker, haciendo de reportero del mismo canal, define a Rumania como "el culo del mundo" (Quintuples 2000 [SP, T4.E4]).

\subsection{Escenificación de la noticia}

Al ser la televisión un medio eminentemente visual, la información emotiva gana presencia y esto condiciona la selección de los sucesos que se abordan. Es por ello que en los informativos abundan las imágenes espectaculares de desastres naturales y provocados, encuentros deportivos, protestas y otros acontecimientos multitudinarios y llamativos y las declaraciones con una gran carga emocional y sentimental. No obstante, cuando las noticias en sí mismas no ofrecen un espectáculo visual, los presentadores y reporteros suelen adoptar un lenguaje corporal exagerado, una locución rápida, un tono de voz alto y con énfasis dramáticos a fin de llamar la atención de la audiencia sin perder un minuto.

Tom Tucker, ya mencionado por su exageración de los contenidos, además destaca por su capacidad de crear tensión y expectativa donde no la hay. En El beso más visto 
en el mundo (PF, T3.E8), Tucker anuncia que un profesor fue sorprendido abusando de sus alumnos y, después de una larga pausa, añade que con alocadas teorías. La verdadera noticia es que el profesor fue arrestado por enseñar una teoría de la evolución no aprobada en Estados Unidos de América; pero como dicho suceso carecía de emoción, Tucker decide atraer al público agravando las razones del arresto y mencionado el abuso a menores. En E. Peterbus Unum (PF, T2.E18), Tucker va un paso más allá y, mientras informa del conflicto entre Estados Unidos y el nuevo estado de Petoria, hace ruidos con un silbato y un plástico de burbujas para intentar imitar el sonido de bombas y metralletas y así simular que está en medio de una guerra.

Kent Brockman, la figura más longeva y reconocida del periodismo animado, también sobresale por sus dotes interpretativas. En Lisa sobre hielo (LS, T6.E8), después de una secuencia de imágenes de explosiones, aparece Brockman corriendo hasta su silla. Agitado y enérgico, el presentador anuncia: "Hola, soy Kent Brockman. Esta noche podrán ver la tremenda explosión...”. Brockman hace una pausa y continua diciendo: “... en el precio de la madera". Eleva el tono de la voz y añade: "El Presidente Reagan muere...". Nuevamente hace una pausa, mucho más larga que la anterior, y continua diciendo: “... de celos, según afirma Trudeau en la crítica de su nuevo musical, pero antes, hagamos el balance de muertes provocadas por la asesina tormenta que nos golpea con su metralleta cargada de nieve". El chico del tiempo anuncia que, de momento, la cifra de muertos es cero pero invita a la audiencia a ser paciente porque rápidamente subirá por las nubes. Como es evidente, el informativo no cuenta con ninguna noticia impactante, de manera que Brockman se ve obligado a recurrir a un tono de voz muy alto, explotar su expresividad facial, acercarse a la cámara, organizar las palabras de manera que se cree tensión y hacer largas pausas antes de continuar para que la audiencia no cambie de canal. Por el contrario, en Edición aniñada (LS, T9.E21), Brockman muestra su cara más sensible, pero no menos manipuladora. Brockman confiesa a Bart que las historias que hacen ganar premios son las de interés humano, aquellas que, según el mismo Brockman, van directo al corazón y nublan la mente. Para enseñarle como se escribe esta clase de historias, Brockman le muestra un video en el que aparece presentando una noticia sobre la demolición de un tiovivo. El presentador aparece delante de la atracción infantil y dice: “¿Escuchan? Es el sonido de las risas de los niños...". Hace una pausa y añade: “... silenciada, ya que mañana este tiovivo, que ha sido deleite de niños y jóvenes americanos por más de seis años, será demolido para dejar paso al futuro: una tienda de alfombrillas para ratones de ordenador". Brockman, que hace cara de consternado, acaricia uno de los caballos del tiovivo mientras afirma: "En el mundo moderno, por lo visto, no queda hueco para este anciano jamelgo. Pero si no les importa, este antiguo niño se dará una última vuelta". Sube sobre uno el caballo y el tiovivo empieza a girar, mientras de fondo se escucha la canción Turn!, Turn!, Turn! de The Byrds (1965). En definitiva, Brockman intenta convertir un hecho trivial en un reportaje conmovedor.

\subsubsection{Reporteros del sensacionalismo}

La influencia del periodismo sensacionalista a los informativos se ha traducido también en un aumento significativo de conexiones en directo. El empleo de esta herra- 
mienta no siempre se justifica por las necesidades o relevancia de los acontecimientos, sino para hacer ostentación de recursos técnicos y reforzar la idea del informativo como espectáculo de la inmediatez. Por ejemplo, en el episodio Espaldas pringosas (SP, T8.E7), aparece una secuencia que parodia la cadena de noticias CNN, en el que se informa sobre la llegada de un ser del futuro. Desde el estudio de grabación del informativo, Aaron Brown, el presentador, conecta en directo con cuatro reporteros: Christina Naylon, desde la puerta del hospital en el que están examinando al misterioso ser del futuro; Brad Morgan, desde dentro del hospital; Harrison Moore, desde el portal del tiempo por el que llegó la criatura y Chris Holt, desde otro estudio. La importancia de la noticia es indiscutible y, sin caer en el sensacionalismo, es posible justificar su amplia cobertura. No obstante, la información que ofrecen los reporteros es absolutamente superficial, carece de análisis y contexto. Por ejemplo, Harrison Moore explica el funcionamiento del portal del tiempo en función de las reglas espaciotemporales descritas en Terminator (James Cameron, 1984), Regreso al futuro (Robert Zemeckis, 1985) y Timerider (William Dear, 1982). Tal como indica Mariano Cebrián, "el directo sólo ofrece la apariencia de los hechos y oculta el trasfondo, la causalidad, las consecuencias" (Cebrián Herreros, 2004: 27).

Tricia Takanawa, reportera de "Channel 5 Action News", informativo de Padre de familia, representa a la perfección el corresponsal sensacionalista que describe Calabrese (2000: 48): es enviada a cualquier sitio, por remoto que sea, para aportar espectacularidad al informativo; es siempre la primera en llegar al lugar de los hechos; es capaz de cualquier cosa por conseguir una historia y de hacer una nota sobre cualquier cosa, puesto que en dichas notas la relevancia informativa no es imprescindible.

Takanawa, a diferencia del resto de sus compañeros, siempre tiene una actitud muy seria, estoica y nunca se deja llevar por las emociones delante de las cámaras, lo que implica un gran esfuerzo por su parte, ya que el hecho de ser reportera de campo la obliga a enfrentarse cada día a cosas muy diversas. Sin embargo, éste es el único indicio de profesionalidad de la reportera. En la mayoría de sus apariciones, Takanawa ha informado sobre hechos carentes de importancia. Por ejemplo, en La hija de Peter (PF, T6.E7) entrevista a un hombre que va a todas partes en su bicicleta de 10 velocidades y en Mr. Caballero del sábado (PF, T3.E9) hace una entrevista al bufón de la Feria Medieval. Incluso, cuando informa sobre acontecimientos relevantes, presenta segmentos insustanciales y carentes de profundidad de análisis y perspectiva. Por ejemplo, en Stewie ama a Lois (PF, T5.E1) le asignan hacer un reportaje sobre la epidemia de gripe que está azotando Quahog. Sin embargo, como ella misma tiene la gripe, la nota consiste en verla a ella vomitando en el váter de su casa.

Tricia Takanawa también representa a los reporteros capaces de cualquier cosa por informar. En Brian enamorado (PF, T2.E4), por ejemplo, mantiene relaciones sexuales con un desconocido (Quagmire) para hacer un reportaje sobre sexo anónimo. Además, es la primera en llegar al lugar de la noticia, incluso cuando ésta está en pleno desarrollo. Es el caso de Vivir y morir en Dixieland (PF, T3.E12), episodio en el que Takanawa informa de la fuga de un prisionero de la cárcel de Quahog mientras dicha fuga está teniendo lugar. Tricia Takanawa aparece presentando desde el lado exterior de la reja que rodea la cárcel, junto a un agujero en el suelo. Del agujero sale el pre- 
sidiario y Takanawa lo entrevista rápidamente. El hecho que la reportera supiera el sitio exacto por el que saldría el fugitivo y que no aprovechará la ocasión para evitar su fuga muestra cómo las ansias de Takanawa por obtener una primicia están por encima de cualquier otra consideración, incluso la seguridad pública.

Nancy Hicks Gribble es otra gran representante del reportero sensacionalista, aunque no cuenta con todos los años de trabajo de campo de Takanawa. En el episodio Lo que el huracán se llevó (RC, T9.E13), se desata un incendio cerca de Arlen y Nancy, degradada a operadora de la línea telefónica del tiempo, ve la oportunidad de volver a estar delante de las cámaras. Junto a su marido, Dale, y su mejor amiga, Peggy, Nancy Hicks roba una furgoneta de la cadena, equipada con todos los instrumentos de transmisión, infringe las medidas de seguridad y accede a la zona más afectada por el incendio. Desde allí, la audiencia vive minuto a minuto el desastre forestal y es testigo del estado de desesperación y agonía al que llega Nancy, convencida de una muerte segura abrasada por las llamas. Al final, Nancy Hicks Gribble y sus acompañantes son rescatados y las imágenes del incendio conseguidas por Nancy Hicks baten los récords de audiencia de la cadena, razón por la cual es ascendida de chica del tiempo a copresentadora del informativo. Mientras Nancy Hicks Gribble se encuentra en medio de la catástrofe, vemos, desde la central de la cadena, que la señal de la trasmisión es inestable. El director del informativo pide a todo el personal que haga todo lo posible para no perder la imagen ya que, él mismo asegura, ésta pondrá a la cadena en lo más alto. De hecho, da la orden de que dichas imágenes se conviertan en el buque insignia de la cadena y aparecen en todas las pautas promocionales hasta navidad.

En Nancy se va a Dallas (RC, T13.E13), Nancy Hicks Gribble es enviada a realizar un reportaje en una escuela local sobre un niño y su mascota. Cansada de informar siempre sobre mascotas adorables que no hacen ganar premios Emmy, Nancy decide cambiar el tono de su reportaje de forma repentina. Después de presentar al niño y a su zarigüeya, Nancy pregunta al niño como consiguió pasar los controles de seguridad de la escuela. El niño, sorprendido, le pregunta que cuales controles y, a partir de aquí, Nancy abandona su dulce tono de voz. Mirando a la cámara, con actitud preocupada, Nancy asegura que la pregunta que acaba de hacer el niño es la misma que se hacen muchas escuelas: ¿Dónde están los controles de seguridad? Con música dramática de fondo, Nancy continua su reportaje afirmando que Billy (el niño) y Orange (la zarigüeya) representan el recuerdo de la terrible tragedia que podía haber ocurrido hoy en la escuela: "Si este niño hubiese sido un intruso y este marsupial un arma, la historia hubiese sido muy diferente". El reportaje, tal y como indica Hank, que lo ve desde casa, es una concatenación de suposiciones y conjeturas sin sustento alguno. Sin embargo, todo el pueblo encuentra la nota muy convincente, la cadena consigue 12 nuevos afiliados y Nancy es contratada por KUMT, el canal de noticias más importante del estado de Texas.

Según Calabrese (2000: 48), la introducción de musicalización, efectos visuales como cámaras subjetivas, tomas cortas y rápidas, cámara lenta, efectos de sonido y recursos de diseño y edición, reduce considerablemente el tiempo de los reporteros para informar, lo que los obliga a ser más interpretativos y emotivos de lo que han sido 
jamás. Y esto es precisamente lo que hace Nancy, emplea recursos de forma y de fondo que apelan a los sentimientos y a los sentidos más que a la razón, se deja llevar por sus emociones para así emocionar también al público y mantenerlo enganchado a un hecho sobre el que en realidad no está siendo informado. Tal como resume Kent Brockman en unos de sus momentos de lucidez: "Los reporteros solían exponer la corrupción y la avaricia corporativa. Ahora, como bebés sin dientes, jse amamantan de la desinformación y hacen caca en un pañal llamado llamamos las noticias de las seis!" (Kent no siempre puede decir lo que quiere [LS, T18.E22]).

\subsection{Intereses económicos y políticos}

El periodismo sensacionalista explota el sentido y la calidad de la información con la finalidad de aumentar su audiencia, así como asegurar la inversión por parte de sus anunciantes. La eficacia de las noticias de impacto para atraer a la audiencia es innegable, pero no todos los días hay noticias de este tipo, ni mucho menos las suficientes para llenar un espacio televisivo entero. No obstante, con técnicas como la del cebo, los programas de información se aseguran que la audiencia esté atenta durante toda la emisión y vea todos los anuncios hasta el final. En Bart se hace famoso (LS, T5.E12), por ejemplo, Brockman presenta el informativo diciendo: "En las noticias de esta noche, un cierto tipo de refresco que puede llegar a ser letal. Pero no les diremos cuál hasta después de los deportes y el clima con el divertido Sonny Tormenta". Y en Me encanta ese trofeo (PF, T2.E5), Tom Tucker anuncia que se ha encontrado al verdadero asesino de la ex mujer de O. J. Simpson, pero que su identidad sólo será revelada después de un reportaje de Tricia sobre el festival de la cosecha. De esta manera, ambos presentadores pospone una información impactante solo para evitar que los telespectadores cambien de canal y tengan que ver todo el informativo hasta el final. Por el contrario, en Ella era mi chica (LS, T16.E4), Brockman se deja de rodeos y se dirige directamente a la audiencia diciendo: "El Canal 6 de noticias es lo más. Una persecución de coches cada noche o la chica del tiempo aparece con una camiseta escotada. Y si no lo hace, le regalamos una pizza". De manera semejante, los reporteros de South Park no dudan en hacer promoción publicitaria durante sus noticias de mayor audiencia. Por ejemplo, en iFeliz Navidad Charlie Manson! (SP, T2.E16), durante la percusión policial a Manson por parte de la policía, el reportero del canal Nebraska News dice que esas sorprendentes imágenes son presentadas por cortesía de “Snacky S'mores” y añade: “iDeliciosos malvaviscos en una crujiente galleta!”. Más adelante, en el mismo episodio, mientras se encuentra delante de la casa en que Mason tiene a los rehenes, el reportero vuelve a interrumpir diciendo: "Me gustaría recordarles que esta crisis de rehenes en vivo es patrocinada por Palmoral Sun Block. Recuerden, si no es Palmoral, usted tendrá cáncer".

De forma paralela, los intereses políticos del presentador y el informativo también son puestos en relieve para atraer la atención de un público y unos anunciantes concretos. Por ejemplo, en el episodio Krusty caballero sin espada (LS, T14.E14), se introduce una de las numerosas secuencias paródicas que llama la atención sobre la estrecha relación entre Fox News y el partido Republicano. En dicho episodio, la familia ve en Fox News un debate entre los candidatos de Springfield al Congreso. 
Krusty, el candidato republicano, es presentado con una especie de aureola brillante rodeándole la cabeza y una enorme bandera americana hondeando en el fondo, mientras el presentador dice: "Representando a los republicanos, el animador amado por los niños, Krusty el payaso". Por su parte, Armstorng, el candidato demócrata, aparece con unos cuernos de diablo sobreimpresos, una bandera soviética a un lado y es presentado como: "Ese tío". El presentador trata al candidato demócrata de "camarada" y lo acusa de tener un punto de vista adultero solo por señalar que Krusty aun no ha ganado las elecciones. Y por si fuera poco, algunos de los titulares que aparecen en la parte inferior de la pantalla dicen: "Las noticias sin sentido aumentan un 37\%", “Los demócratas producen cáncer? Averígüelo en Foxnews.com", "Estudio: 92\% de los demócratas son homosexuales" y "JFK se une de forma póstuma al partido Republicano".

\section{Conclusiones}

Tal y como hemos mostrado en cada uno de los apartados del análisis de la construcción del discurso periodístico, las comedias animadas de prime time exhiben de forma muy ilustrativa los diferentes rasgos característicos del periodismo audiovisual sensacionalista que ha acabado de tomar forma en las dos últimas décadas.

El periodismo moderno se ha constituido como relato social de referencia general. Por eso mismo, existe una clara relación entre la calidad de las narraciones periodísticas hegemónicas y la garantía de una opinión pública informada y crítica. El objetivo de hacer posible el acceso general a una información veraz, plural, completa y contrastada es uno de los retos de las democracias en el actual contexto de mutación social impulsado, en parte, por el impacto de las tecnologías interactivas de la comunicación. Una de las paradojas más significativas de la opulencia comunicativa consolidada por el protagonismo social de las comunicaciones audiovisuales e interactivas es el empobrecimiento interpretativo y la dudosa credibilidad de buena parte de la oferta. No existe una relación directa entre cantidad y calidad informativa. De hecho, muy a menudo, una sobreoferta de información periodística no seleccionada y contextuada adecuadamente o directamente sensacionalista acaba funcionando como desinformación.

Precisamente, este es uno de los aspectos en los que las comedias animadas de prime time demuestran una capacidad de crítica social basada en la parodia televisiva. Los informativos de estas comedias ilustran de forma sistemática y pedagógica el protagonismo de los criterios que priman la trivialización y banalización de la información. Sus periodistas televisivos han copiado el tono de voz y la entonación, las pausas y los comentarios habituales de presentadores ampliamente reconocidos. Pero al llevar al límite su afán por ser siempre el centro de atracción y la obsesión por batir récords de audiencia, recurren constantemente al sensacionalismo y la espectacularización banal de la información. La imagen del presentador como profesional reflexivo, conocedor, asertivo, honesto, responsable, imparcial y comedido cede paso a un modelo de periodista que desmitifica la figura del presentador de noticias, invierte los criterios de valoración periodística, seduce a la audiencia con sus dotes interpretativas, editorializa las noticias y es capaces de exagerar el hecho más nimio hasta hacerlo pasar por una noticia de máxima relevancia. Como resultado nos mues- 
tran unos informativos literalmente esperpénticos, pero perfectamente reconocibles. Y ese es, precisamente, su objetivo transgresor y pedagógico.

Efectivamente, las comedias animadas de prime time analizadas no se limitan a perseguir objetivos cómicos. Con su empleo sistemático de la parodia, muestran de manera muy efectiva cómo los informativos polarizan, maquillan, maximizan o deforman la realidad. Siempre en clave humorística, invitan amablemente a la audiencia a ser consciente de ello. Y, de esta manera lúdica, la equipa para hacer una lectura crítica de los informativos. En otras palabras, nos enseña a leer textos informativos televisivos. Cumplen una función de alfabetización televisiva desde la propia televisión. Obviamente, un proceso de alfabetización a través de la propia televisión no tiene como objetivo desarrollar una crítica mediática del mismo registro o profundidad que la que permiten las teorías académicas. Pero hemos comprobado que no las contradicen: las secuencias informativas de las comedias de prime time estudiadas ilustran con sorprendente fidelidad los conceptos desarrollados por las investigaciones académicas de referencia. Y por ello, acaban actuando con los efectos propios de una eficaz teoría crítica aplicada del periodismo televisivo.

\section{Referencias bibliográficas}

ALTER, John (1999): "The new powers that be". Newsweek, 18 de enero, pp. 14-15.

BARRIS, Alex (1976): Stop the presses! The newspaperman in American films. New York, A.S. Barnes \& Co.

BIRD, Elizabeth (2000): "Audience demands in a murderous market. Tabloidization in US television news", en SPARKS, Colin y TULLOCH, John (eds.): Tabloid tales. Global debates over media standards. Lanham, MD, Rowman and Littlefield, pp. 213-28.

BEZUNARTEA, Ofa et al., (2007): "Periodistas de cine y de ética". Ámbitos, no 16, pp. 369-393.

BRANTS, Kees (1998): “Who's afraid of infotainment?" European Journal of Communication, vol. $13, \mathrm{n}^{\circ} 3$, pp. 315-335.

CALABRESE, Andrew (2000): "Political space and the trade in television news", en SPARKS, Colin y TULLOCH, John (eds.): Tabloid tales. Global debates over media standards. Lanham, MD, Rownan \& Littlefield, pp. 43- 61.

CEBRIÁN HERREROS, Mariano (2004): La información en televisión. Obsesión mercantil y política. Barcelona, Gedisa.

CICERÓN, Marco Tulio (2002): Sobre el orador. Madrid, Gredos.

CORWIN, Norman (1986): Trivializing America. The triumph of mediocrity. Secaucus, NJ, Lyle Stuart.

DANIEL, Douglass K. (1996): Lou Grant: The Making of TV's Top Newspaper Drama. Syracuse, NY, Syracuse University Press.

DÍAZ NOSTY, Bernardo (dir., 2006): Tendencias'06. Medios de Comunicación. El año de la televisión. Madrid, Fundación Telefónica. 
DIJK, Teun A. van (1990): La noticia como discurso. Compresión, estructura y producción de la información. Barcelona, Paidós.

DIJK, Teun A. van (1980): Texto y contexto. Semántica y pragmática del discurso. Madrid, Cátedra.

EHRLICH, Matthew C. (1997): "Journalism in Movies". Critical Studies in Mass Communication, Vol. 14, pp. 267-281.

EHRLICH, Matthew C. (2004): Journalism in the Movies. Urbana y Chicago, University of Illinois Press

FISKE, John (1992): "Popularity and the politics of information", en DAHLGREN, Peter y SPARKS, Colin (eds.): Journalism and popular cultura. London, Sage, pp. $45-63$.

FRANKLIN, Bob (1997): Newszak and news media. London, Arnold.

GARCÍA AVILÉS, José Alberto (2007): "El infoentretenimiento en los informativos líderes de audiencia de la Unión Europea". Anàlisi, n 35, pp. 47-63.

GENCEL, Mine (2004): "Tabloidization of news media. An analysis of television news in Turkey". European Journal of Communication, vol. 19, n 3, pp. 371- 386.

GLYNN, Kevin (2000): Tabloid culture. Trash taste, popular power, and the transformation of American television. Durham: Duke University Press.

GOOD, Howard (1989): Outcasts: The Image of Journalists in Contemporary Film. Lanham, MD, Scarecrow.

GOOD, Howard (1998): Girl Reporter: Gender, Journalism and Movies. Lanham, $\mathrm{MD}$, Scarecrow.

GOOD, Howard (2000): The Drunken Journalist: The Biography of a Film Stereotype. Lanham, MD, Scarecrow.

HARTLEY, John (1996): Popular reality. Journalism, modernity, popular cultura. London, Arnold.

LABIO BERNAL, Aurora (2008): "Periodismo de entretenimiento. La trivialización de la prensa de referencia". Estudios sobre el mensaje periodístico, vol. 14. Madrid, Servicio de Publicaciones de la Universidad Complutense, pp. 435-447.

LANGER, John (2000): La televisión sensacionalista. El periodismo popular y las "otras noticias". Barcelona, Paidós.

LÓPEZ DE ZUAZO ALGAR, Antonio (1985): Diccionario del periodismo. Madrid, Pirámide.

LUMBY, Catharine (1999): Gotcha. Life in a tabloid world. Sydney, Allen and Unwin.

MARTÍNEZ DE SOUSA, José (1981): Diccionario general del periodismo. Madrid, Paraninfo.

MCNAIR, Brian (2010): Journalists in film. Heroes and villains. Edinburg, Edinburgh University Press. 
NESS, Richard (1997): From Headline Hunter to Superman: A Journalism Filmography. Lanham, MD, Scarecrow.

ORTOLOVEA, Peppino (1995): Un ventenio a colori. Televisione privata e societá in Italia (1975-1995). Milán, Giunti.

PRADO, Emili (2003): "La espectacularización de la realidad", en El anuario de la televisión. Madrid, GECA, pp. 178-186.

QUINTILIANO, Marco Fabio (2004): Instituciones oratorias. Alicante, Biblioteca Virtual Miguel de Cervantes.

SALTZMAN, Joe (2003): "Sob sisters. The image of the female journalist in popular culture", en The image of the journalist in popular culture (IJPC), en: http://ijpc.org/page/sobsmaster.htm. [fecha de consulta: 15 de mayo de 2013]

SPARKS, Colin y TULLOCH, John (2000): Tabloid tales. Global debates over media standards. Lanham, MD, Rownan \& Littlefield.

SUNKEL, Guillermo (2001): La prensa sensacionalista y los sectores populares. Bogotá, Norma.

TURNER, Graeme (1999): "Tabloidization, journalism and the possibility of critique". International Journal of Cultural Studies, vol. 2, no 1, pp. 59-76.

WINSTON, Brian (2002): "Towards tabloidization? Glasgow revisited, 1975-2001". Journalism Studies, vol. 3, nº 1, pp. 5-20.

ZOONEN, Liesbet Van (1998): "A day at the zoo. Political communication, pigs and popular culture". Media, Culture and Society, vol. 20, nº. 2, pp. 183-201. 